\title{
512 マルチボディダイナミクス理論を用いたトラッククレーンの振動制御 Vibration control of a truck crane based on multi-body dynamics model.
}

\author{
○学 原井 篤志 (徳大院) 正 日野 順市 (徳大工) \\ 正 芳村 敏夫 (徳大工) 正 栗本 政雄 (徳大工)
}

Atsushi Harai; School of Engineering, The University of Tokushima, Minamijosanjima-cho 2-1, Tokushima 770-8506, Japan Junichi Hino, Toshio Yoshimura, and Masao Kurimoto; Factory of Engineering, The University of Tokushima

Key words : A truck crane, Multi-body dynamics, Fuzzy control, SIRMs fuzzy reasoning

\section{1. 緒言}

マルチボディダイナミクス(剛体多体系)理論は、コンピュー 夕を利用した機構解析の理論として、1980年代から発展し てきたが、近年の計算機速度および数値計算手段の進歩により、 近年さかんに研究が行われるようになってきた。

本研究では、局所座標系やオイラー角、オイラーパラメータ を用いて運動方程式を導出し、3次元運動に対するクレーンモ デルを作成する。また、そのモデルを用いて、ブームの位置決 めおよび吊り荷の振れ止め制御を行う。また、今回は制御力の 決定方法として、ブームの位置決めには 2 入力型のファジィ制 御、吊り荷の振れ止めには SIRMs ファジィ制御を用いる。

2. 連動学 (1).(2)

2. 1 オイラー角とオイラーパラメータ

本研究では、3次元 body の姿勢を表すパラメータとしてオ イラー角とオイラーパラメータを用いる。これらを用いること によって、ある座標系の原点が基準座標系の原点と一致してい れば、 $2 つ の$ 座標系は一致し、 $x, y, z$ 軸のどの軸まわりに回転 させても、基準方向からある量だけ回転させることで、それら を任意の方向に向けることができる。

オイラ一角の定義には何種類かあるが、ここでは $z-y-z$ 形 のオイラ一角 $\gamma=\left[\begin{array}{lll}\phi & \theta & \phi\end{array}\right]^{T}$ を定義する。 $z-y-z$ 形は、最初 $z$ 軸まわりに $\phi$ 回転させ、つぎに $y$ 軸まわりに $\theta$ 回転させ、さ らに $z$ 軸まわりに $\phi$ 回転させて任意の姿勢を作り出すもので ある。最終的な座標系から最初の座標系への変換マトリクス $\boldsymbol{A}$ は

$A=\left[\begin{array}{ccc}\cos \phi \cos \theta \cos \phi-\sin \phi \sin \phi & -\cos \phi \cos \theta \sin \phi-\sin \phi \cos \psi & \cos \phi \sin \theta \\ \sin \phi \cos \theta \cos \phi+\cos \phi \sin \phi & -\sin \phi \cos \theta \sin \phi+\cos \phi \cos \phi & \sin \phi \sin \theta \\ \sin \theta \sin \phi & \sin \theta \sin \phi & \cos \theta\end{array}\right]$

となる。また、原点を共有する $2 つ$ 座標系において、 $\Sigma$ をあ る単位ベクトル $\boldsymbol{u}$ まわりに回転角 $\chi$ だけ回転することで、 $\Sigma^{\prime}$ に一致させることができる。このとき

$$
e_{0}=\cos \frac{\chi}{2}, e=\left[\begin{array}{l}
e_{1} \\
e_{2} \\
e_{3}
\end{array}\right]=u \sin \frac{\chi}{2}
$$

と定義する。この $e_{0}, e$ をオイラーパラメータと呼ぶ。オイラー パラメータは 4 個であり、空間の自由度は 3 であるから、オイ ラーパラメータには拘束 $e_{0}{ }^{2}+e_{1}{ }^{2}+e_{2}{ }^{2}+e_{3}{ }^{2}=1$ が課される。 オイラーパラメータをまとめて $p=\left[e_{0}, e_{1}, e_{2}, e_{3}\right]^{T}$ と表すこと にすると、 $\boldsymbol{A}$ は

$$
\boldsymbol{A}=2\left[\begin{array}{ccc}
e_{0}^{2}+e_{1}^{2}-\frac{1}{2} & e_{1} e_{2}-e_{0} e_{3} & e_{1} e_{3}+e_{0} e_{2} \\
e_{1} e_{2}+e_{0} e_{3} & e_{0}^{2}+e_{2}^{2}-\frac{1}{2} & e_{2} e_{3}-e_{0} e_{1} \\
e_{1} e_{3}-e_{0} e_{2} & e_{2} e_{3}+e_{0} e_{1} & e_{0}{ }^{2}+e_{3}^{2}-\frac{1}{2}
\end{array}\right]
$$

と表される。また、オイラーパラメータにより次のような $2 つ$ の重要なマトリクスを定義することができる。

$$
\begin{gathered}
\boldsymbol{E} \equiv\left[-\boldsymbol{e}, \tilde{\boldsymbol{e}}+e_{0} \boldsymbol{I}\right]=\left[\begin{array}{cccc}
-e_{1} & e_{0} & -e_{3} & e_{2} \\
-e_{2} & e_{3} & e_{0} & -e_{1} \\
-e_{3} & -e_{2} & e_{1} & e_{0}
\end{array}\right] \\
\boldsymbol{G} \equiv\left[-\boldsymbol{e},-\tilde{\boldsymbol{e}}+e_{0} \boldsymbol{I}\right]=\left[\begin{array}{cccc}
-e_{1} & e_{0} & e_{3} & -e_{2} \\
-e_{2} & -e_{3} & e_{0} & e_{1} \\
-e_{3} & e_{2} & -e_{1} & e_{0}
\end{array}\right]
\end{gathered}
$$

\section{23 次元運動の基本的な拘束}

ここで、3 次元の body $i$ と body $j$ についての 4 つの基本的 な拘束を示す。

(1) bodyに固定されたべクトルが直交している。

$$
\Phi^{d 1}\left(a_{i}, a_{j}\right)=a_{i}^{T} a_{j}=a_{i}^{\prime T} A_{i}^{T} A_{j} a_{j}^{\prime}=0
$$

(2) body に固定されたベクトルと両 body を結ぶベクトルが 直交している。

$$
\begin{aligned}
\Phi^{d 2}\left(a_{i}, d_{i j}\right) & =a_{i}^{T}\left(r_{j}+A_{j} \boldsymbol{s}_{j}^{\prime P}-r_{i}-A_{i}{\boldsymbol{s}_{i}^{\prime P}}^{P}\right) \\
& =a_{i}^{\prime T} A_{i}^{T}\left(\boldsymbol{r}_{j}+A_{j} \boldsymbol{s}_{j}^{{ }^{P}}-\boldsymbol{r}_{i}\right)-\boldsymbol{a}_{i}^{\prime T} \boldsymbol{s}_{i}^{{ }^{P}}=0
\end{aligned}
$$

(3) 2 つの body が 1 点を共有している。

$$
\boldsymbol{\Phi}^{S}\left(P_{i}, P_{j}\right)=\boldsymbol{r}_{j}+\boldsymbol{A}_{j} \boldsymbol{s}_{j}^{\prime P}-\boldsymbol{r}_{i}-\boldsymbol{A}_{i} \boldsymbol{s}_{i}{ }^{P}=0
$$

\begin{tabular}{|c|c|c|c|c|}
\hline & $\Phi_{i}$ & $\Phi_{r_{j}}$ & $\Phi_{n_{i}}$ & $\Phi_{n_{j}}$ \\
\hline$\Phi^{d 1}\left(a_{i}, a_{j}\right)$ & 0 & 0 & $-a_{j}^{\prime T} A_{j}^{T} A_{i} \tilde{a}_{i}^{\prime}$ & $-\boldsymbol{a}_{i}^{T} \boldsymbol{A}_{i}^{T} \boldsymbol{A}_{j} \tilde{a}_{j}^{\prime}$ \\
\hline$\Phi^{d 2}\left(a_{i}, d_{i j}\right)$ & $-\boldsymbol{a}_{i}^{\boldsymbol{i}^{T}} \boldsymbol{A}_{i}^{T}$ & $a_{i}^{, T} A_{i}^{T}$ & $\left(a_{i}^{T}{\widetilde{s_{i}}}^{P}-d_{i j}{ }^{T} A_{i} \tilde{a}^{\prime}\right)$ & $-a_{i}^{{ }^{T}} A_{i}{ }^{T} A_{j} s_{j}{ }_{j}^{P}$ \\
\hline$\Phi^{s}\left(P_{i}, P_{j}\right)$ & $-I$ & $I$ & $A_{i} \widetilde{s}_{i}^{p}$ & $A_{j} \widetilde{s}_{j}^{p p}$ \\
\hline$\Phi^{S S}\left(P_{i}, P_{j}, C\right)$ & $-2 d_{i j}{ }^{T}$ & $2 d_{i j}{ }^{T}$ & $2 d_{i j}{ }^{T} A_{i} \widetilde{s}_{i}^{P}$ & $-2 d_{i j}{ }^{T} A_{j} \widetilde{s}_{j}^{\prime P}$ \\
\hline
\end{tabular}

(4) 2 つ body が一定の距離を保って運動する。

$$
\Phi^{s s}\left(P_{i}, P_{j}, C\right)=d_{i j}{ }^{T} d_{i j}-C^{2}=0
$$

また、Table.1 に基本拘束の $\boldsymbol{\Phi}_{r_{i}}, \boldsymbol{\Phi}_{r_{i}}, \boldsymbol{\Phi}_{\boldsymbol{x}_{i}^{\prime}}, \boldsymbol{\Phi}_{\boldsymbol{x}_{i}^{\prime}}$ を示す。

$$
\text { Table.1 } \Phi_{r_{i}}, \Phi_{r_{j}}, \Phi_{x_{i}}, \Phi_{x_{j}^{\prime}} \text { of the basic restriction }
$$

3. 運動方程式 ${ }^{(1),(2)}$

たがいに拘束を持つ $n b$ 個の body について

$$
\begin{aligned}
& \boldsymbol{r}=\left[\boldsymbol{r}_{1}{ }^{T}, \boldsymbol{r}_{2}{ }^{T}, \cdots, \boldsymbol{r}_{n b}{ }^{T}\right]^{T} \\
& \boldsymbol{p}=\left[\boldsymbol{p}_{1}{ }^{T}, \boldsymbol{p}_{2}{ }^{T}, \cdots, \boldsymbol{p}_{n b}{ }^{T}\right]^{T}
\end{aligned}
$$

とすると、運動方程式は

$$
\left[\begin{array}{ccc}
M & 0 & \Phi_{r}^{T} \\
0 & J^{\prime} & \Phi_{\boldsymbol{x}^{\prime}}{ }^{T} \\
\Phi_{r} & \Phi_{\boldsymbol{z}^{\prime}} & 0
\end{array}\right]\left[\begin{array}{c}
\ddot{\boldsymbol{r}} \\
\dot{\omega}^{\prime} \\
\lambda
\end{array}\right]=\left[\begin{array}{c}
\boldsymbol{F}^{A} \\
\boldsymbol{n}^{\prime A}-\widetilde{\omega}^{\prime} J^{\prime} \omega^{\prime} \\
\gamma
\end{array}\right]
$$

となる。一方、オイラーパラメータによる表現は

$$
\left[\begin{array}{cccc}
M & 0 & \Phi_{r}{ }^{T} & 0 \\
0 & 4 G^{T} J^{\prime} G & \Phi_{p}{ }^{T} & \Phi_{p}^{p^{T}} \\
\Phi_{r} & \Phi_{p} & 0 & 0 \\
0 & \Phi_{p}^{p} & 0 & 0
\end{array}\right]\left[\begin{array}{c}
\ddot{r} \\
\ddot{p} \\
\lambda \\
\lambda^{p}
\end{array}\right]=\left[\begin{array}{c}
F^{A} \\
2 G^{T} n^{\prime A}+8 \dot{G}^{T} J^{\prime} \dot{G} p \\
\gamma \\
\gamma^{p}
\end{array}\right]
$$


である。式(12)の最後の式はオイラーパラメータの拘束式の加 速度方程式である。ここで重要なことは、式(11)を用いて市を 求めても、心は積分可能でないことである。そこで、式(12)よ り $\ddot{\nabla}$ と $\ddot{p}$ を求め、半陰的ルンゲクッタ法を用いることにより『 とpを求めていく。しかし、これだけでは各要素の角速度と角 加速度を求めることができないので、次に示寺式(13)を用いる ことによっでとpを求めていく。

$$
\omega^{\prime}=2 G \dot{p}, \quad \dot{\omega}^{\prime}=2 \mathbb{G} \dot{p}
$$

\section{4. 制御法 ${ }^{(3)}$}

本研究では、トラッククレーンモデルにおけるブームの位置 決めを 2 入力型のファジィ制御を用いて行い、吊り荷の振れ止 めを SIRMs ファジィ制御を用いて行う。

今回用いた 2 入力型ファジィ制御則を以下に示す。

rule $i$ : if $x_{i}$ is $A_{i 1}$ and $x_{2}$ is $A_{i 2}$ then $y$ is $B_{i}$

つぎに、SIRMs ファジィ制御則は

SIRMs $-i:\left\{R_{i}: \text { if } \alpha_{i} \text { is } A_{j}^{i} \text { then } \beta_{i} \text { is } b_{j}{ }^{\prime}\right\}_{j=1}^{m_{i}}$

また、2入力型のファジィルールを Table.2に、SIRMs ファジィ ルールを Table.3に示す。さらに2入力型のファジィ制御におけ るメンバーシップ関数を Fig.1 に示す。また、SIRMsファジィ制 御におけるメンバーシップ関数を Fig.2 に示す。ここで、Fig.1、 Fig.2において、(a)は前件部のメンバーシップ関数、(b)は後件部 のメンバーシップ関数をそれぞれ表している。

Table.2 Double inputs Fuzzy rules Table.3 SIRMs Fuzzy rules

\begin{tabular}{|c|c|c|c|}
\hline & NB & ZO & PB \\
\hline NB & NB & NS & ZO \\
\hline ZO & NS & ZO & PS \\
\hline PB & ZO & PS & PB \\
\hline
\end{tabular}

\begin{tabular}{|c|c|}
\hline & \\
\hline $\mathrm{NB}$ & $\mathrm{NB}$ \\
\hline $\mathrm{ZO}$ & $\mathrm{ZO}$ \\
\hline $\mathrm{PB}$ & $\mathrm{PB}$ \\
\hline
\end{tabular}

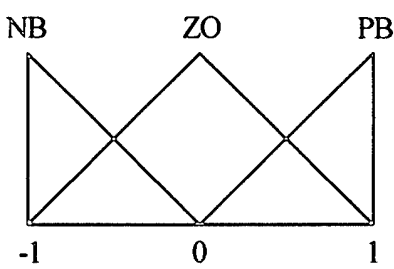

PB

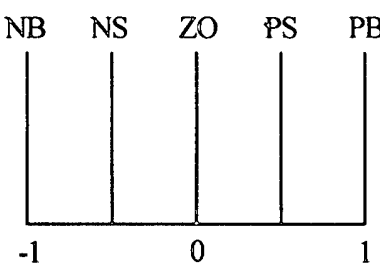

Fig.1 Membership function of the Double Inputs Fuzzy sets
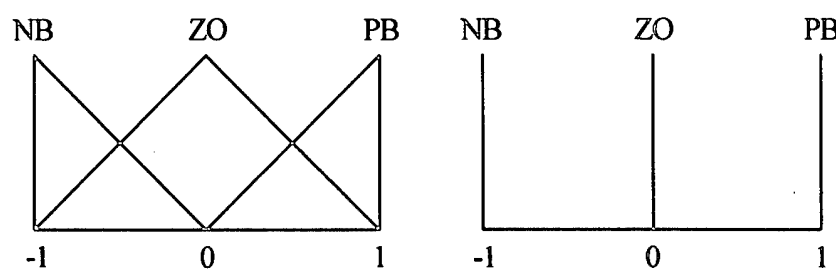

Fig.2 Membership function of the SIRMs Fuzzy sets

5. シミュレーション

Fig.3は、本研究で用いたトラッククレーンモデルについて簡 略化したモデルである。body 1 を基嘫部、body 2 をブーム部、 body 3〜5 をロープ部、body 6 を吊り荷とする。また、Fig.3に 示すように body 1 の重心を全体座標の原点とし、各body の重 心を局所座標の原点とする。

本研究ではロープ部を 3 等分して考えることにより、よりロ 一プらしい動きを出せるようにした。Fig.3における関節のうち、 body 2 と body 3 をつないでいる関節のみ球関節である。残りの 関節はすべて回転関節とする。

シミュレーションでは、ブームを $30^{\circ}$ から $60^{\circ}$ まで起伏させ る。計算時間は $10[s]$ 、刻み時間は $0.001[s]$ とした。また、そ のときの Fig.3 における各初期パラメータをTable.4に示す。

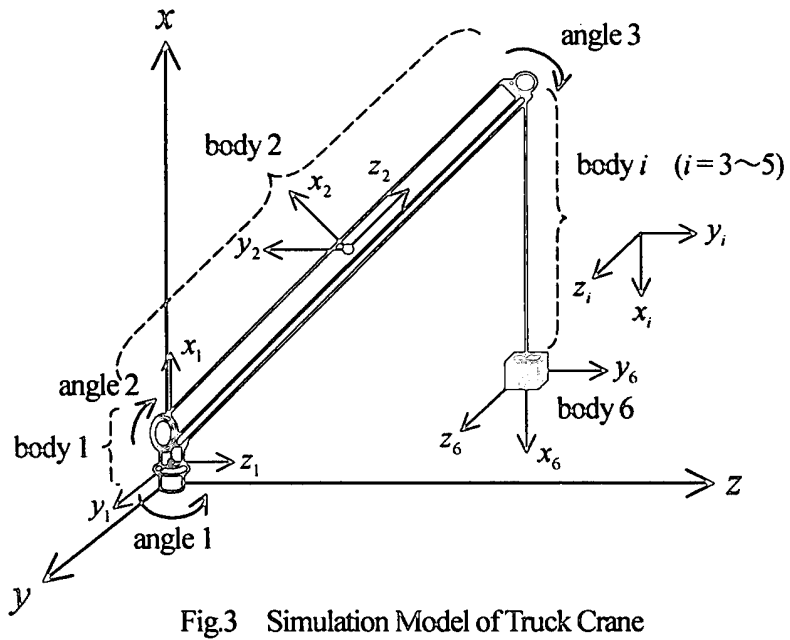

Fig.3 Simulation Model of Truck Crane

Table.4 Parameter of Crane Miodel

\begin{tabular}{|c|c|c|}
\hline & Length & Mass \\
\hline \hline body 1 & $0.083[\mathrm{~m}]$ & $0.6[\mathrm{~g}]$ \\
\hline body 2 & $0.8[\mathrm{~m}]$ & $0.194196[\mathrm{~g}]$ \\
\hline body $3 \sim 5$ & $0.02[\mathrm{~m}]$ & $0.03[\mathrm{~g}]$ \\
\hline body 6 & $0.0294[\mathrm{~m}]$ & $0.1[\mathrm{~g}]$ \\
\hline
\end{tabular}

Fig.4はブームの重心の変位を示している。ここで、(a)は $\mathrm{x}$ 方向 変位、(b)は $\mathrm{z}$ 方向変位を表している。また、Fig.5 は吊り荷の変 位を示している。(a)は $\mathrm{x}$ 方向変位、(b)は $\mathrm{z}$ 方向変位を表してい る。 (a)

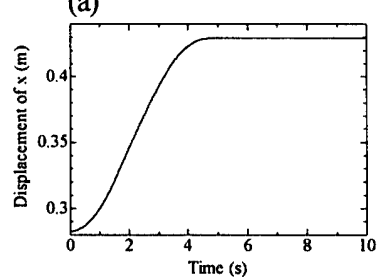

(b)

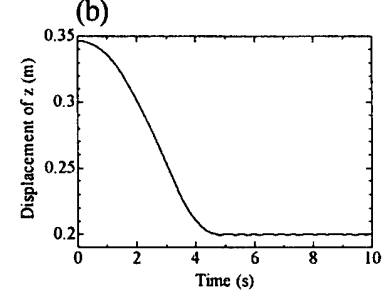

Fig.4 Displacement of body 2 (a)

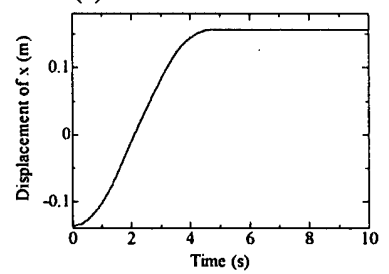

(b)

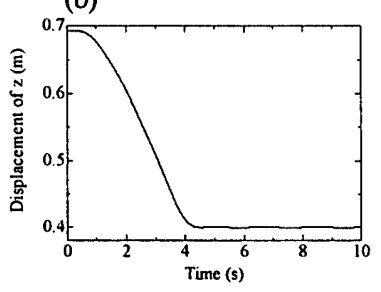

Fig.5 Displacement of body 6

\section{6. 結言}

本研究では、クレーンの 3 次元運動モデルを構築するため、 局所座標系やオイラーパラメータを用いて運動方程式を導出し た。また、そのモデルをおいて 2 入力型のファジィ制御と SIRMs ファジィ制御を用いて、ブームの位置決めと吊り荷の振れ止め を行った。シミュレーションの結果、ブームの位置決めおよび 吊り荷の振れ止めにおいて良好な結果が得られた。

参考立缡

1）造山茂樹著、機械のダイナミクス、コロナ社（1993）

2）E.J. ハウグ著、コンピュータを利用した機構解析の基本、 大河出版 (1996)

3）ファジィ制御、日本ファジィ学会（1993） 